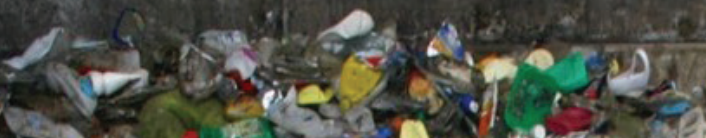

A.

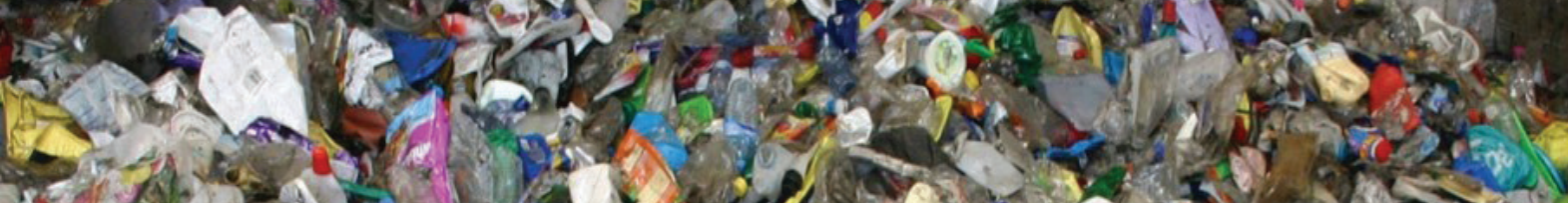

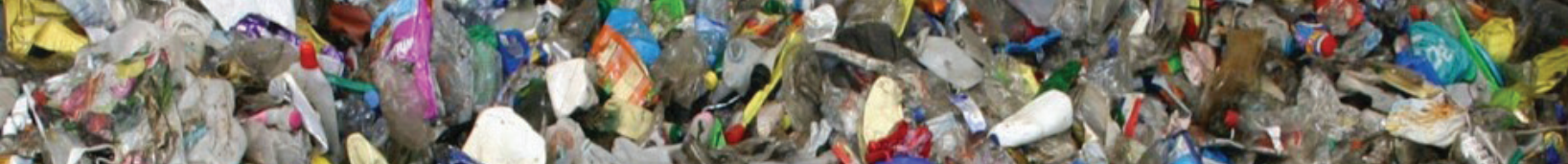

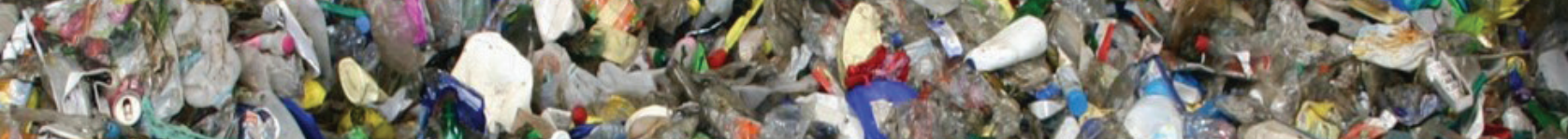

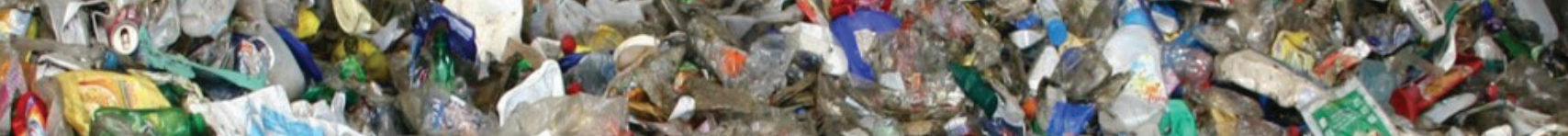

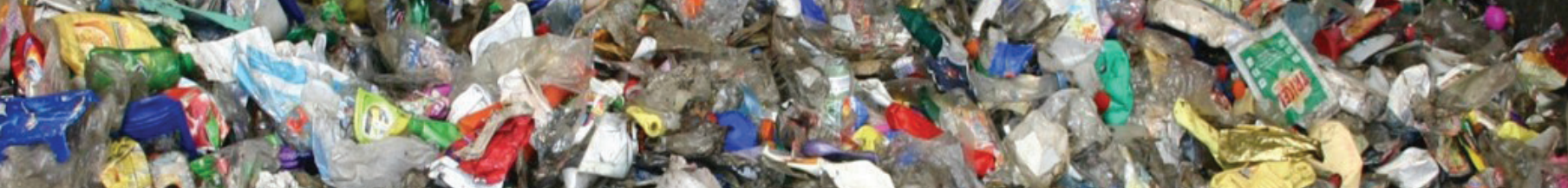

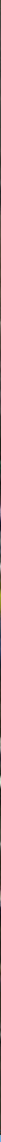

Sorting protocol for packaging wastes

dr. E.U. Thoden van Velzen, ir. M.T. Brouwer and D. Huremovic MSc.d

WAGENINGEN

UNIVERSITY \& RESEARCH 



\section{Sorting protocol for packaging wastes}

Authors: dr. E.U. Thoden van Velzen, ir. M.T. Brouwer and D. Huremovic MSc.d

Institute: Wageningen Food \& Biobased Research 
Version: final

Reviewer: Arie van der Bent

Approved by: Arie van der Bent

Client: n.a.

Sponsor: n.a..

This report can be downloaded for free at https://doi.org/10.18174/451703 or at www.wur.eu/wfbr (under publications).

(C) 2018 Wageningen Food \& Biobased Research, institute within the legal entity Stichting Wageningen Research.

The client is entitled to disclose this report in full and make it available to third parties for review. Without prior written consent from Wageningen Food \& Biobased Research, it is not permitted to:

a. partially publish this report created by Wageningen Food \& Biobased Research or partially disclose it in any other way;

b. (let a third party) use this report created by Wageningen Food \& Biobased Research or the name of the report or Wageningen Food \& Biobased Research in whole or in part for the purposes of making claims, conducting legal procedures, for (negative) publicity, and for recruitment in a more general sense;

c. use the name of Wageningen Food \& Biobased Research in a different sense than as the author of this report.

PO box 17, 6700 AA Wageningen, The Netherlands, T + 31 (0)317 4800 84, E info.wfbr@wur.nl, www.wur.eu/wfbr. Wageningen Food \& Biobased Research is part of Wageningen University \& Research.

All rights reserved. No part of this publication may be reproduced, stored in a retrieval system of any nature, or transmitted, in any form or by any means, electronic, mechanical, photocopying, recording or otherwise, without the prior permission of the publisher. The publisher does not accept any liability for inaccuracies in this report. 


\section{Contents}

$\begin{array}{ll}\text { Summary } & 4\end{array}$

1 Introduction $\quad 5$

1.1 The scientific relevance of waste compositions $\quad 5$

$\begin{array}{lll}1.2 & \text { Objective of this sorting protocol } & 6\end{array}$

$\begin{array}{llc}1.3 & \text { General remarks } & 6\end{array}$

$2 \quad$ Origin and handling of samples $\quad 7$

2.1 Type of samples and sampling $\quad 7$

$\begin{array}{ll}2.2 & \text { Handling of the samples }\end{array}$

$\begin{array}{lll}2.3 & \text { Facilities, equipment and materials } & 8\end{array}$

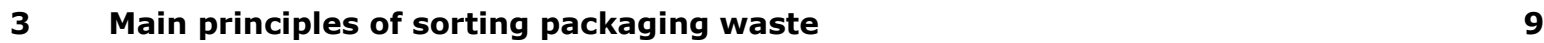

3.1 General rules for sorting packaging waste 9

3.2 Issues during object-wise sorting 9

$\begin{array}{ll}3.3 & \text { Packaging versus non-packaging articles } \\ 3.4 & 10\end{array}$

$\begin{array}{ll}3.4 & \text { Levels of complexity - objects and components } \\ \end{array}$

3.4.1 Disassembling packages into components 10

3.4.2 Product residues and attached moisture \& dirt $\quad 10$

$4 \quad$ Sorting protocol $r$

4.1 Sorting on material type $\quad 12$

4.2 Sorting beverage cartons $\quad 12$

$\begin{array}{lll}4.3 & \text { Sorting plastic objects } & 13\end{array}$

4.3.1 NIR assisted sorting on main plastic type. $\quad 13$

4.3.2 Sorting on plastic packaging types 14

4.3.2.1 Sorting of PE in packaging and article types 14

4.3.2.2 Sorting of PP in packaging and article types $\quad 15$

4.3.2.3 Sorting of PET into packages and article types $\quad 15$

4.3.2.4 Sorting of PS into packages and article types $\quad 15$

4.3.2.5 Sorting of PVC into packages and article types 16

4.3.2.6 Sorting of the other plastics into packages and article types 16

$\begin{array}{lll}4.4 & \text { Sorting non-ferrous metal articles } & 17\end{array}$

$\begin{array}{llr}4.5 & \text { Finalising after sorting } & 17\end{array}$ 


\section{Summary}

This sorting protocol describes a method to analyse post-consumer packaging waste samples in a relatively large detail. This detailed description of these lightweight packaging (LWP) wastes is required to provide compositional data which is required input data in material flow analysis. The protocol starts with describing the general requirements needed to study LWP in detail. Subsequently the method is described. This methodology is relative complex and laborious for LWP that contains plastic packages and is composed of three steps: sorting to main material by visual recognition, sorting into main polymer type with NIR and finally sorting into packaging type. 


\section{Introduction}

\subsection{The scientific relevance of waste compositions}

Since the seventies of the last century post-consumer packaging wastes are separately collected, sorted and recycled. It started with packaging glass and paper \& board which were initially collected via drop-off containers. Later also kerbside collection schemes emerged for especially paper \& board. From the nineties on, separate collection schemes emerged in various EU member states that targeted post-consumer plastic packages, beverage cartons and even metal packages. This is often referred to as the collection of lightweight packaging (LWP) materials. In most EU member states the municipalities are legally obliged to organise the waste collection and hence also the collection of postconsumer packaging wastes. In many cases this implies that they execute the collection and crossdocking themselves and in other cases they delegate this to private companies. Since there are many different municipalities also many different waste collection systems have developed over the past decades. For post-consumer packaging wastes the applied collection schemes can be categorised according to the following list of parameters:

- Portfolio: only plastic packages or also beverage cartons, etc.

- Method: drop-off or kerbside

- Carrier: bags, mini-containers (wheelie bins), loose in a crate or box etc.

- Collection frequency: weekly, fortnightly, four weekly, etc.

- Financial triggers for the collection of MSW, such as pay as you throw

All these different collection schemes in different municipalities generate different gross collection yields, which are officially registered and documented. However, these gross yields cannot be compared in a meaningful manner in case the collection portfolio is not identical. Hence for a more scientific analysis of these collection schemes and their yields the composition of the materials needs to be determined.

Additionally, the perspective on the collection of post-consumer packaging wastes is gradually changing. Up to a few years ago, the main goal of these separate collection schemes was the diversion of recyclable materials from mixed MSW towards recycling. A few years ago the concept of circular economy evolved and a wide range of stakeholders became much more interested in the quality of the separately collected materials and hence in a method to determine the quality.

Besides collected packaging materials also the intermediate products made from them need to be sorted to analyse and describe collection and recycling networks. These intermediate products are named sorting products in the trade. In the Netherlands these sorting products have to comply to the chosen DKR specifications [DSD 2016] and there are several analysing crews that determine the composition of these sorting products to assess whether or not they comply to the specifications. These compositions determined by commercial sorting crews to test compliance, however, leave many questions unanswered. Hence for scientific purposes it is relevant to analyse these sorting products in a much greater level of detail to understand the sorting fates of packages and the quality aspects of sorted products.

Since separately collected packaging materials and sorted products are mainly composed of objects with dimensions in the $1-25 \mathrm{~cm}$ size range, their composition can best be studied by sorting them as loose objects and hence the need for a sorting protocol emerged to determine the composition of packaging wastes in a reliable and reproducible manner. This document describes the sorting protocol as it has been developed within WFBR from 2008 on during the cause of many different projects. In 2013 a first sorting protocol was released [Thoden van Velzen 2013]. The basis of this protocol is still correct. But this updated version of the sorting protocol addresses a few of the practical problems we 
encountered in sorting packaging wastes. Two major changes have been addressed in the sorting protocol; the division between packaging and non-packaging articles and the sorting of laminated plastic films. Additionally within a few projects on beverage cartons and metal packages we noticed that a more dedicated fine sorting was required to describe these packaging wastes. This protocol describes a method to study these materials also in a higher level of detail.

\subsection{Objective of this sorting protocol}

This sorting protocol describes the method in which packaging waste samples are sorted for the purpose of rendering reliable and reproducible compositional data sheets. Our objective as technical scientists is to understand the material composition of waste samples and to use this data as input for a Material Flow Analysis. Hence, the composition of packaging waste needs to be understood in categories with the same material composition. This is relatively straight-forward for packaging wastes that are primarily composed of glass and paper \& board and little categories have to be discerned. However, for especially packaging wastes which contain plastic packages, beverage cartons and metal packages the situation is much more complex and much more sorting categories have to be discerned to describe the material composition of these wastes effectively.

Other stakeholders have different objectives with regard to compositional information. For the Dutch monitoring agency Nedvang compliancy of sorted products to the specifications is the predominant question and hence they have developed a much more straight-forward sorting protocol [Nedvang 2016].

Sorting companies are much more interested in whether or not collected materials contain contaminants and whether or not contaminant threshold values are exceeded, hence the federation Dutch Waste companies drafted a document named acceptance criteria for collected packaging waste, which is in fact a sorting protocol [Vereniging Afvalbedrijven 2017].

Other stakeholders such as Stichting Afvalfonds are more interested in the share of materials that should not be in the recycling system, such as residual waste components and non-packaging objects [Leenaars et al. 2016, Leenaars et al. 2017].

Stakeholders such as municipalities, collection agencies are much more interested in the level of recyclability of packages and want to have these packages sorted along the lines of what is recyclable and what is not [Brouwer et al. 2017].

This implies that sorting agencies that sort for these stakeholders are likely to follow a different sorting protocol and hence also report compositions with a different categorisation. The sorting protocol that we have develop is by far the most detailed of all and can also be used to answer the questions of all the stakeholders.

\subsection{General remarks}

This sorting protocol was written to document the sorting method used at Wageningen Food \& biobased Research with respect to analysing LWP samples. This protocol has been used in multiple projects, of which the project "Sustainable packages" of KIDV and TiFN was the largest. This is a public report and is written for technical scientists that are interested in analysing LWP waste. This sorting protocol and the report are products of independently conducted scientific analysis of employees of Wageningen Food \& Biobased Research. 


\section{Origin and handling of samples}

\section{$2.1 \quad$ Type of samples and sampling}

This sorting protocol is intended for the analysis of post-consumer packaging wastes; the collected materials, the mechanically recovered concentrates and the sorted products made from them. But obviously this protocol can also applied for related materials and wastes in which packaging materials form a minor constituent such as mixed MSW, ONF (the fine waste fraction from a mechanical recovery facility), RDF etc. In the latter case, it is usually wise to first sort out the organic and putrescible waste components, to weigh and remove them.

This sorting protocol starts with the presence of a sample of post-consumer packaging materials and hence doesn't deal with the method of sampling itself. In several publications statistical methods are explained on estimating the minimum amount of samples that is required to analyse the composition reliable [Gallardo et al. 2018, Feil et al. 2017, Nedvang 2016]. The minimum sample weight for postconsumer packaging samples is usually $20 \mathrm{~kg}$ (minimum), since the average article weight is 20 grams and the lowest concentration at which contaminants have to be determined is $0.1 \%$ in the specification for PET bottles (DKR 325 and 328-1).

\subsection{Handling of the samples}

Most samples of packaging waste that we receive for analysis arrive in $1 \mathrm{~m}^{3}$ bigbags with a polyethylene internal bag. Some samples of especially light weight film wastes arrived in closed 240 liter plastic bags and only sparsely we received whole bales of sorted packaging materials. Since postconsumer packaging wastes are moist and the moisture is an integral part of these wastes, we prefer to keep the samples in a refrigerated cell at $7^{\circ} \mathrm{C}$ and to make sure that the bigbag contains a polyethylene internal bag and / or the samples are packed in closed polyethylene bags to minimise moisture loss. Furthermore, post-consumer packaging wastes are biologically active, they sustain both microbiology and insects when stored under ambient conditions. Storing at $7^{\circ} \mathrm{C}$ reduces the biological activity and makes the samples less dangerous to handle for the sorting crew.

Post-consumer packaging wastes pose several health risks for researchers that sort these materials which can be controlled by choosing the correct safety measures and personal protection tools.

Post-consumer packaging waste should be treated as biological hazardous materials. The risk of infections can be minimised by wearing protective clothes, gloves, safety goggles, mouth caps and or face masks. The lab coats should be washed at least weekly and hands should be washed with disinfectants before starting and after finishing the sorting tasks. Additionally tetanus vaccinations should be administrated to employees regularly. Additionally, the laboratory in which the waste samples are stored and sorted need to have an air refreshment system, to avoid the accumulation of malodorous vapours.

A second potential hazard is the risk of cutting. Several packaging waste types offer a larger risk of inflicting cutting wounds, such as metal packaging waste and glass cullets. When sorting these type of packaging wastes special protective gloves should be wore that minimise the risk of cutting hands and fingers. Although plastic packaging waste contains far less objects with sharp edges, still sharp objects 
can be present, like syringes, medical waste, glass cullets etc. The general advice is to sort carefully and also wear protective gloves.

\subsection{Facilities, equipment and materials}

Sorting of post-consumer packaging wastes can best be performed in a closed laboratory with air circulation and an entrance sluice with a washing table and lab coat hangers. The closed space reduces the risk odour emissions and the spread of infectious materials to other work spaces. Since samples are at least $20 \mathrm{~kg}$ in size each and the average object size is roughly 20 grams, the sorting of one single sample takes at least a few hours to several days. Therefore it is highly recommended to work with sorting tables of the right height. The sorters should be able to change between a sitting and standing working position by having chairs on the correct height.

Sorting is performed efficiently with large plastics crates that can be placed on the sorting table. Rigid plastic crates can be labelled for each sorting category and can be washed after use.

Since the type of plastics cannot reliably be determined visually, a near infrared (NIR) plastic detector is required to sort plastics. Some sorters only sort by visually checking for the recycling symbols, but unfortunately the symbols are not always used in the correct manner and we would strongly advise the use of a NIR scanner anyway. We use table top NIR scanners named IOSYS SIRO, which are fast and reliable (http://www.iosys-seidel.de/en/siro.html). The use of NIR scanners implies that we also get a category of plastics that could not be recognised with NIR, these are mainly black coloured, but also can have other dark colours or were highly polluted.

After the sample has been sorted the constituents have to be weighted separately and their weights have to registered. This requires suitable balances and a clean part of the laboratory in which the weights can be written down on the forms. After sorting the constituents can be recombined or kept separate in different plastic bags. The latter approach is laborious but enables corrections.

List of materials:

- Protective gloves, lab coats, goggles, mouth caps etc.

- Refrigerated cell to store sample

- $\quad$ NIR analyser

- $\quad$ Sorting tables

- $\quad$ Sorting crates

- Balances

- Magnet

- Ruler

- Plastic bags to store sorted products in

- $1 \mathrm{~cm}$ screen for manual operation 


\section{$3 \quad$ Main principles of sorting packaging waste}

This chapter describes the basic principles of sorting packaging wastes, the general rules, the issues commonly encountered and the more detailed analysis in components and attached residues.

\subsection{General rules for sorting packaging waste}

Four general rules apply to the sorting of packaging waste:
1. The working space should be kept clean and organised.
2. The employees need unlimited access to personal protection tools like gloves, safety goggles, mouth caps, lab coats, etc.
3. The sorters need to wash and disinfect their hands and remove their lab coats when exiting the sorting lab.
4. Both the sample bags and the bags with sorted products should always be marked with the project name, the sample name, the date of sampling and the content of the bag.

\subsection{Issues during object-wise sorting}

The main principle of object-wise sorting is visual recognition of materials. This is therefore the basis of the first step in sorting packaging waste. Most materials are easily recognised by all sorters and this needs no further explanation: metals, glass, paper \& board, plastic, organic waste, textiles, etc. Three problems occur during sorting on visual characteristics: multi-material objects, too small objects to be recognised and other materials that lie outside the categorisation.

\section{Multi-material objects}

Many objects are composed of multiple materials. In fact if you take a closer look you will probably find that most objects are composed of multiple materials. The golden rule to categorise an object is to first find the heaviest component and add the multi-material object to the category of its heaviest component. Hence a filled vacuum cleaner bag is made on the outside of a textile, but its contents are much more heavy indefinable dusts, so the correct categorisation will be "organic waste and indefinable residues".

Agglomerates are a special kind of multi-material objects. Agglomerates are combinations of multiple objects that are in principle loose but have become intertwined, glued or physically connected to each other. Well-known examples are metal cans that have been deformed in the waste collection process and are firmly wrapped around a plastic package. In case there is no special interest in agglomerates, these are separated into the components, unless this was not possible with human force. In the latter case these objects are treated as multi-material objects are sorted to the heaviest component. In some special cases we were especially interested in these agglomerates and then we sorted them to the special category of agglomerates.

\section{Too small objects}

Objects that are too small to be individually sorted are treated as indefinable residues. Of most packaging waste samples a residue is left on the bottom of the bigbag as a sandy and / or organic residue. This is sorted to the level of $1 \mathrm{~cm}$ length scale (in the longest dimension of the object). In case objects are smaller, then these are added to the category of organics and indefinable residues. 
In a few type of samples there is a lot of fine residues, especially in: 'Sorting residues from sorting facilities', 'organic wet fraction of mechanical recovery facilities' and 'glass cullets'. We typically sieve these samples over a $1 \mathrm{~cm}$ screen prior to further handling.

\section{Outside categorisation}

The sorting category 'organics and indefinable residues' is in principle the category for all materials that lie outside the conventional categorisation. Nevertheless surprising objects can be found in collected packaging materials that are sometimes so bizarre or some dominant that the sorting crew keeps these objects separate and also reports them separately. Examples of these additional material categories that have occasionally been found necessary to add to the category list include:

- Minerals, stones, ceramics and bricks

- Diapers

- Leather, shoes

- Natural wood and tree branches

- Disposable Carnival clothes

\subsection{Packaging versus non-packaging articles}

The prime rule to decide whether or not an object is a package or not is whether or not the article was purchased full with product inside and is normally discarded empty without a product inside. Hence, deep freeze storage bags and garbage bags are non-packaging articles, since they are purchased empty and discarded either full or empty.

\subsection{Levels of complexity - objects and components}

Objects are composed of components, product residues and attached moisture and dirt. The coming paragraphs describes methods to determine to composition in a higher level of detail.

\subsubsection{Disassembling packages into components}

Packaging wastes are sorted on the level of objects. Since most packages are multi-material objects and hence are sorted to the heaviest component, it is important to realise that these sorting categories do not contain pure materials. In order to describe the material composition of a sorting category, the packages have to be disassembled into the various components. The materials of all components have to be identified with NIR or IR technology and these components have to weighted. By conducting this procedure for at least 10 different packages that are representative for a sorting category an estimated material composition of a sorting category is obtained [Brouwer et al. 2018, Thoden van Velzen et al. 2016, Thoden van Velzen et al. 2013].

Since some of the packaging components are relatively loose, such as labels and caps, they can be found as separate objects in a sample and hence will be sorting in different categories than the main packaging component.

\subsubsection{Product residues and attached moisture \& dirt}

Contained product residues and attached moisture \& dirt form also an integral part of packaging objects and are also considered as packaging components. So the object is sorted object-wise into a certain sorting category with the attached and contained residues. In several projects it is not only 
relevant to determine the composition of packaging waste in terms of objects, but also to determine the levels of attached moisture and dirt. This is typically performed by taking ten representative packages from the sorted product and weighing their gross weight. Then these ten packages are washed with hot water, dish washing liquid and a brush both inside and outside. These cleaned packages are dried in a large oven at $80^{\circ} \mathrm{C}$ overnight and in the morning the net weight of the packages is weighted. The level of attached moisture and dirt equals the relative weight difference between the gross and the net weight divided by the gross weight, see equation 1.

\section{Equation 1 The level of attached moisture and dirt of packages is calculated from the weight difference relative to the gross weight of the packages.}

Since, 50 different plastic packaging object types are discerned, measuring the LAMD values for all the plastic objects is laborious. Hence, often the LAMD value is measured only of 5 abundant types of plastic packages and these 5 LAMD values are weight-averaged. 


\section{$4 \quad$ Sorting protocol}

\subsection{Sorting on material type}

All post-consumer packaging waste samples are first visually sorted into different materials with the help of the general sorting principles in chapter 3.2. Every object is taken from the sample bag visually inspected and sorted in the right material bin. In case a division has to be made between ferrous and non-ferrous metals, than the metallic object has to be tested on magnetism with a permanent magnet. The sorting decision tree is shown in figure 1. For some samples of post-consumer waste a general material composition suffices and this is the whole routine.

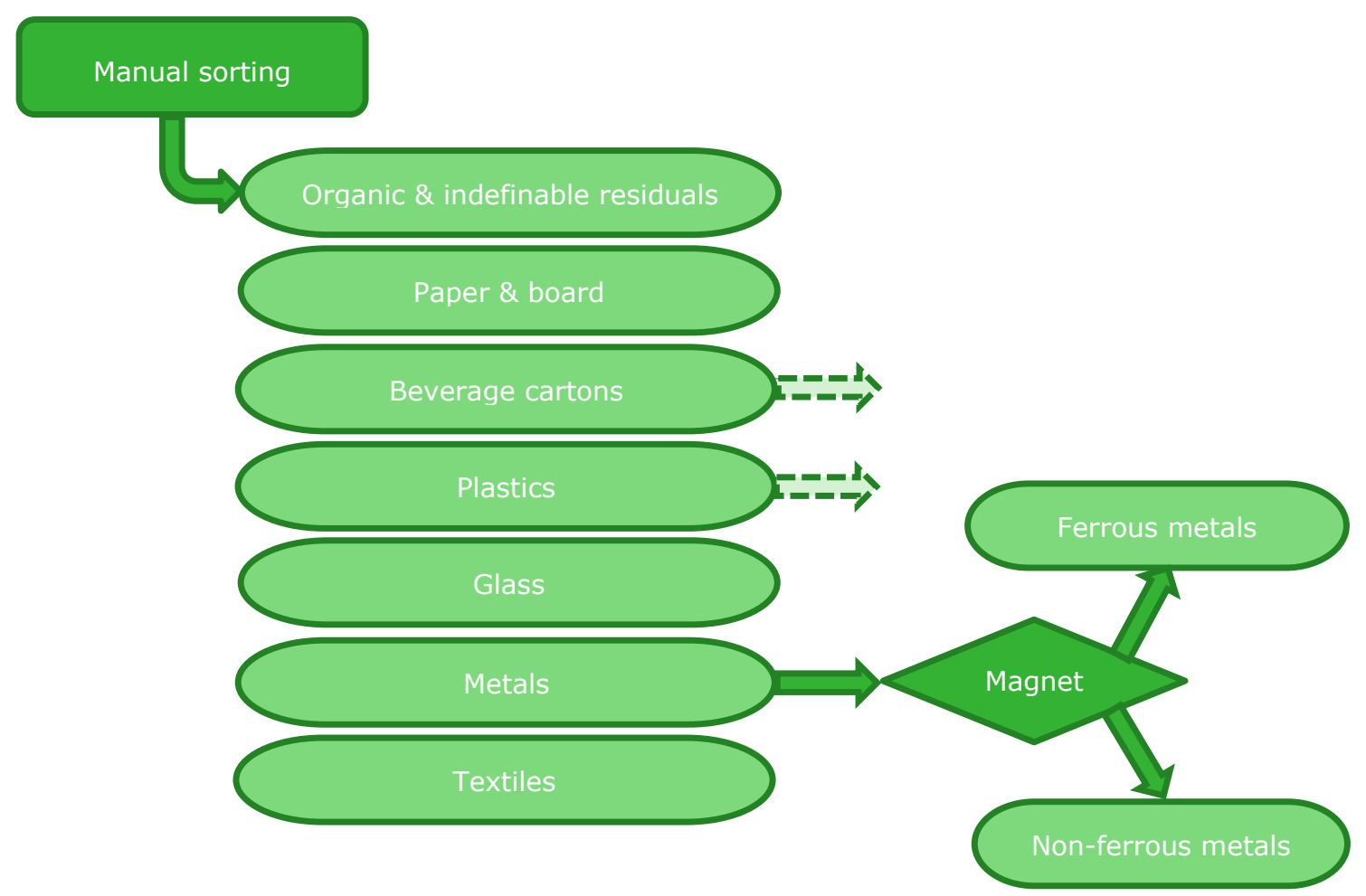

Figure 1 Decision tree for sorting post-consumer packaging wastes on the primary material level.

In many cases, however, the beverage cartons, the plastic objects and/or non-ferrous metal objects have to be analysed further. In these cases the decision tree in figure 1 is the first step in the sorting process. The further analysis of the beverage cartons in explained in paragraph 4.1 and of plastic objects in paragraph 4.2 .

\subsection{Sorting beverage cartons}

Dutch beverage cartons are sorted in 14 categories, see Table 1 . These categories were chosen to reflect the differences in material compositions and LAMD values of the beverage cartons. This categorisation was introduced in 2013 [Thoden van Velzen et al. 2013] and used from then on. An important parameter in the sorting process is whether or not the contained food product was fresh and had a short shelf-life or was sterilised and had a long shelf-life. This is obvious from symbols and texts on the cartons, such as "UHT dairy product". This implies that the carton contains an aluminium layer and hence has a different material composition. In some cases it is not directly clear whether or not the contained food product had been sterilised, in these instances the interior colour of the beverage 
carton is inspected; in case of an aluminium-inside colour the carton is sorted in the category with the UHT treated products.

\section{Table 1: Categorisation of beverage cartons}

\begin{tabular}{l} 
Beverage carton categories \\
Milk cartons $\geq 1 \mathrm{~L}$ \\
\hline Milk cartons $<1 \mathrm{~L}$ \\
UHT milk cartons $\geq 1 \mathrm{~L}$ \\
UHT milk cartons $<1 \mathrm{~L}$ \\
\hline Yoghurt \& dessert cartons $\geq 1 \mathrm{~L}$ \\
Yoghurt \& dessert cartons $<1 \mathrm{~L}$ \\
\hline Juice cartons $\geq 1 \mathrm{~L}$ \\
\hline Juice cartons $<1 \mathrm{~L}$ \\
\hline Cartons with fresh mixes of juice \& diary $\geq 1 \mathrm{~L}$ \\
\hline Cartons with fresh mixes of juice \& diary $<1 \mathrm{~L}$ \\
Cartons with UHT mixes of juice \& diary $\geq 1 \mathrm{~L}$ \\
Cartons with UHT mixes of juice \& diary $<1 \mathrm{~L}$ \\
Cartons for residual products $\geq 1 \mathrm{~L}$ \\
\hline Cartons for residual products $<1 \mathrm{~L}$
\end{tabular}

This categorisation has been used in multiple projects since 2013. Only in one project an additional category was used of "Beverage carton look-a-likes". These are paper \& board packages that have some resemblance of a beverage carton and which civilians could add to a separate collection scheme that aims for beverage cartons. Example of these packages are: folding cartons with a PE liner for frozen vegetables, Pringles crisp tubes, sugar cube cartons etc.

\subsection{Sorting plastic objects}

The sorting process for plastic packages and utensils comprises of two additional steps; a NIR-assisted sorting into main-polymer type and a subsequent visual sorting step into packaging types. Therefore the complete sorting process for post-consumer plastic packaging waste is comprised of three steps. First the sorting on material type by visual recognition as explained in paragraph 4.1 followed by the two steps that are explained in this paragraph.

\subsubsection{NIR assisted sorting on main plastic type.}

Every plastic object is held in the light beam of the NIR scanner. The light beam is targeted on the largest component of the object, hence on what is expected to be the main polymer of the object. The object is held as close as possible to the reflective tile and slowly turned until a clear scanning result is obtained. In most cases a result is given within one second. Large pieces of thin plastic film are folded to obtain a longer optical path for the NIR scanner. The NIR scanner recognises the following polymers: PE, PP, PET, PS, PVC, PLA, PC, PMMA, PA, PUR but also cellulose and several laminated films such as PET-PE, PET-PP, PE-PA and PP-PA. Black and dark-coloured plastics cannot be identified with NIR scanners and these are added to the category for "non-NIR-detectable and residual plastics". During normal sorting operation eight bins are used, namely: PE, PP, PET, PS, PVC, residual plastics (PMMA, PC, PLA etc.), Laminated flexibles and Non-NIR detectable plastics.

The NIR-assisted manual plastic sorting method is executed to mimic industrial NIR sorting. Hence all objects are subjected to NIR scanning, also those that the sorting crew are already familiar with.

Additionally, the result of the NIR scanner is deemed to be more important than any recycling symbols 
or texts on the article. Also darkly coloured plastic packages of which the NIR scanner cannot identify the main polymer and which have a clear recycling symbol are still added to the bin "non-NIR detectable" and not to the bin that corresponds to the recycling symbol. In Annex 1 more detailed guidelines are given for the use of the NIR scanner.

\subsubsection{Sorting on plastic packaging types}

The NIR sorted plastics are manually sorted into the different packaging types. The division in packaging types is coarsely similar for PE, PP, PET, PS and PVC. These are roughly divided in the following main categories: beverage bottles, non-beverage bottles, other rigid packages, flexibles, push-through strips, non-packaging plastics and a few specialties that differ per plastic type. The decision trees for the eight types of plastics are graphically shown in the Annexes and are explained in detail in the sub-paragraphs below.

In general sorters find it easy to differ beverage bottles from non-beverage bottles from other rigid packages (trays, cups, beakers, etc.) and from flexible packages. However, several thermoformed packages are half-way in between being flexible and rigid. Therefore, in case the packages are semiflexible, the packages are added to the other rigid packages category.

Loose packaging components that have been found loose in the sample, are treated as individual objects and are sorted in the category the component belongs to, not where the complete package would belong to.

\subsubsection{Sorting of PE in packaging and article types}

The decision tree for PE is graphically shown in Annex B and the PE-article categories are listed in Table 2. PE is often the largest category when sorting collected plastic packaging materials and hence also 14 different categories are discerned. These categories are grouped in three types: DPP (desired plastic packages), UPP (undesired plastic packages) and NPP (non-packaging plastics).

Table 2: Categorisation of PE plastic articles.

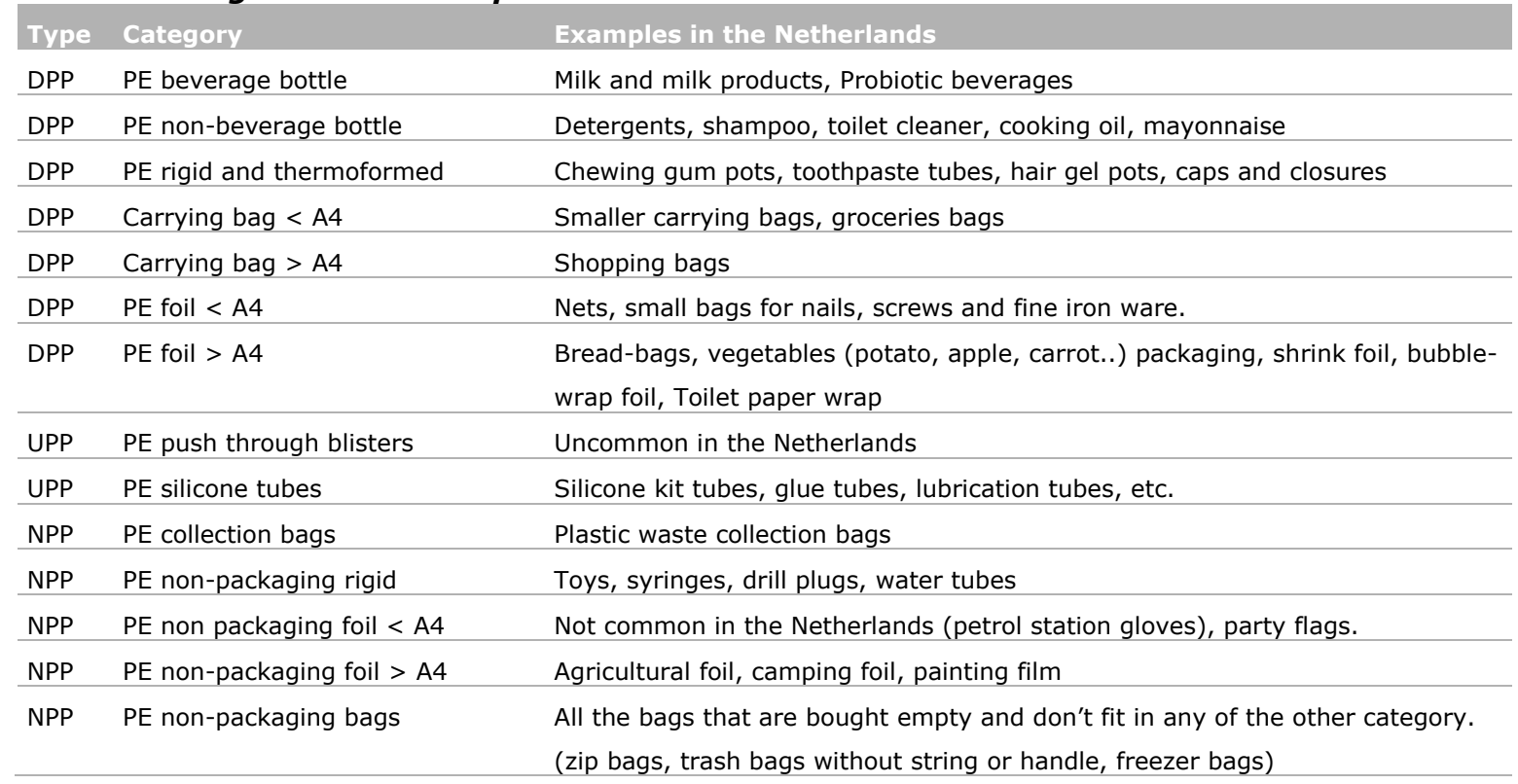

Newly trained sorters often find it difficult to discern PE foils from the PE non-packaging bags. The latter are bags that civilians purchase empty, such as trash bags, lunch bags and freezer bags. Most other PE packages and articles are fairly easy to discern.

Foamed PE film sheets are occasionally used as transport liners in boxes and crates for fruits and vegetables and are hence also occasionally observed in packaging waste samples, these are then 
added to the flexible packages. Bubble wrap is much more common and is also added to the flexible packages.

\subsubsection{Sorting of PP in packaging and article types}

The decision tree for PP is graphically shown in Annex C and the PP-packaging and article categories are listed in Table 3. Only 7 categories are discerned for PP and the most common one for collected materials is PP other rigid packages.

\section{Table 3: Categorisation of the PP plastic articles.}

\begin{tabular}{lll}
$\begin{array}{l}\text { Type } \\
\text { DPP }\end{array}$ & PP beverage bottle & Examples in the Netherlands \\
\hline DPP & PP non-beverage bottle & Detergents, shower gels, shampoo, ketchup \\
\hline DPP & PP other rigid packages & $\begin{array}{l}\text { Cookies trays, butter tubs, ice-cream trays, salad and fruits trays, yoghurt } \\
\text { beakers, mayonnaise bucket, hair gel pots, caps and closures }\end{array}$ \\
\hline DPP & PP foil < A4 & Candy, sweets and pasta packaging, sliced fruits and vegetables, \\
\hline DPP & PP foil > A4 & Big sweets and candy packages, fresh flower sleeves \\
\hline UPP & PP blister packaging & Tablets and chewing gum packaging \\
\hline NPP & PP non-packaging & Fly swatter, flowerpot, toys, pipes, cutlery, straws
\end{tabular}

\subsubsection{Sorting of PET into packages and article types}

The decision tree for PET is graphically shown in Annex D and the PET-package and article categories are listed in Table 4. Usually for PET four types of PET beverage bottles are discerned. In a few studies, we have made an additional distinction in the category of 'non-beverage bottles' for food and non-food non-beverage bottles.

\section{Table 4: Categorisation of the PET plastic articles.}

\begin{tabular}{lll}
$\begin{array}{l}\text { Type } \\
\text { DPP }\end{array}$ & $\begin{array}{l}\text { Category } \\
\text { PET bottle clear } \leq 0.5 \text { litre }\end{array}$ & $\begin{array}{l}\text { Small clear water and soda bottles, including pale-blue coloured water bottles } \\
\text { (Romy, Chaudfontaine, Saskia, Spa) }\end{array}$ \\
\hline DPP & PET bottle coloured $\leq 0.5$ litre & Red \& green bottles, dark-blue Spa bottles, Sprite \\
\hline DPP & PET bottle clear $>0.5$ litre & Large soda and water bottles, juice bottles, clear bottles with sleeves \\
\hline DPP & PET bottle coloured $>0.5$ litre & Large soda and water bottles, green, brown "Hohes C" bottle \\
\hline DPP & PET non-beverage bottle & Fabric softener, Shampoo, shower gels, hand soap, vinegar, oil, dressing \\
\hline DPP & PET other rigid packages & Trays for meat, fish, sliced cheese, cured meats, nuts, tomatoes, soft fruits, \\
\hline DPP & PET foil $<$ A4 & luxury salads \\
\hline DPP & PET foil $>$ A4 & Film that has been separated from top-sealed trays for fruit and salads trays \\
\hline UPP & PET push-through blisters & Uncommon in the Netherlands \\
\hline NPP & PET non-packaging articles & Certain pencil case, stuffed animal toys, Carnival clothes
\end{tabular}

\subsubsection{Sorting of PS into packages and article types}

The PS category is usually relatively small in Dutch packaging waste samples and encompasses a few bottles, beakers, trays, expanded polystyrene (EPS) foam blocks and trays and non-packaging articles. The decision tree is given in Annex $E$ and an overview of the PS packages and article categories are given in Table 5. EPS packages and articles are undesired for the sorting and recycling industries and are hence sorted in separate categories. 
Table 5: Categorisation of the PS plastic articles.

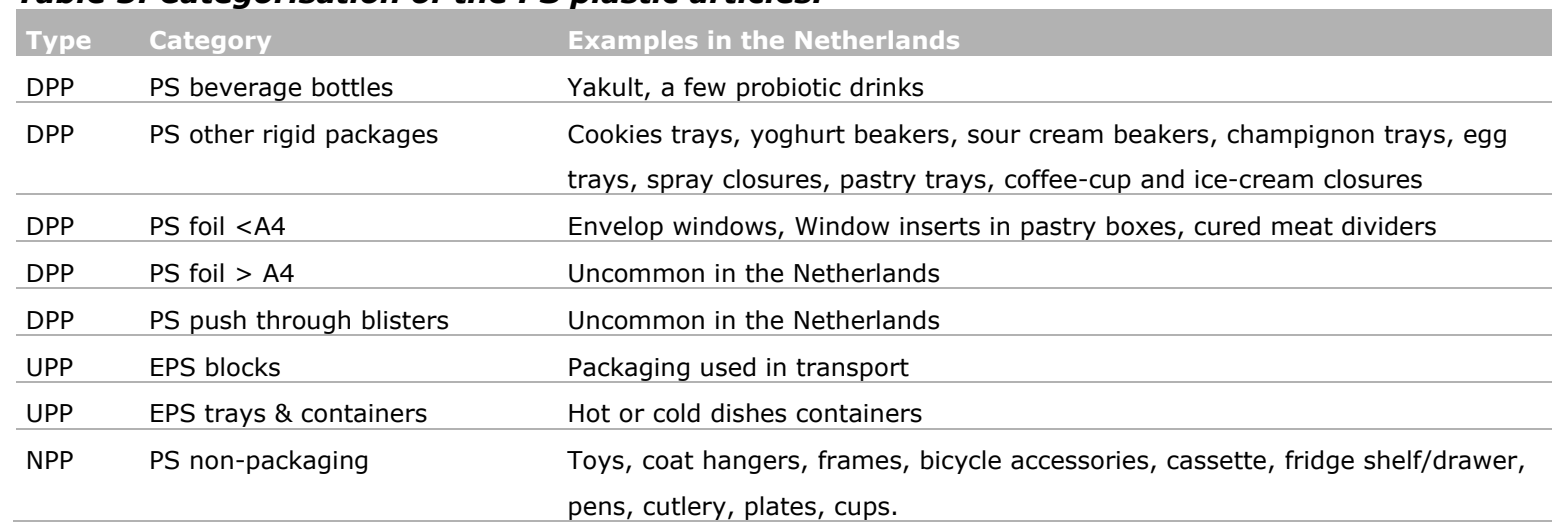

\subsubsection{Sorting of PVC into packages and article types}

The PVC category of post-consumer plastic waste is usually small in the Netherlands and usually consists of push through blisters, stretch-wrap film and non-packaging articles. The decision tree is given in Annex F and an overview of the PVC packages and article categories are given in Table 6.

Table 6: Categorisation of the PVC plastic articles.

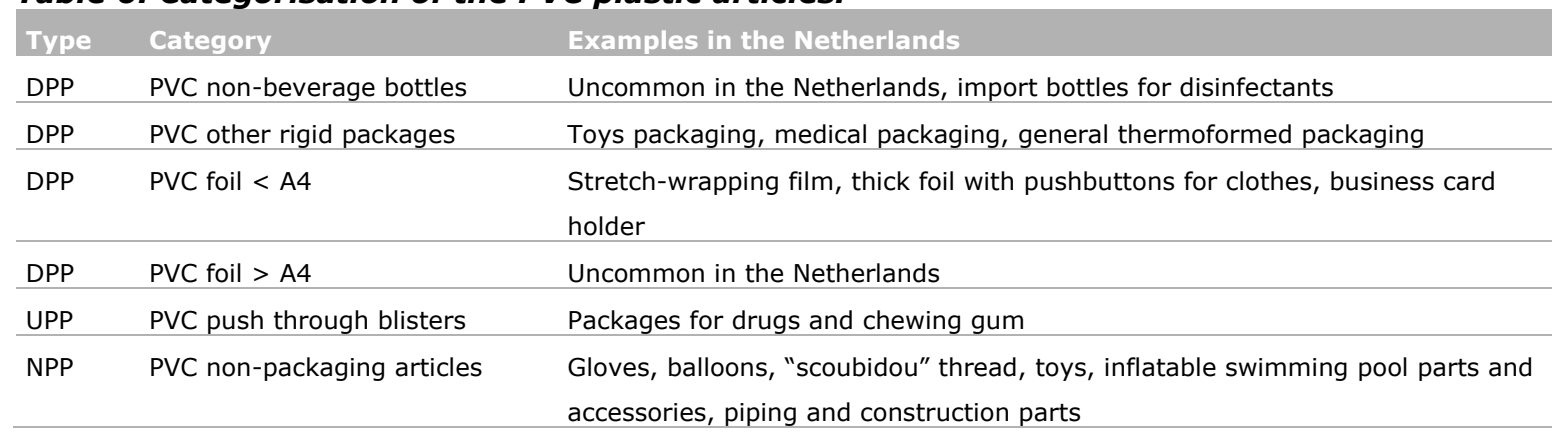

\subsubsection{Sorting of the other plastics into packages and article types}

After PE, PP, PET, PS and PVC have been sorted into packages and articles three residual bins remain; non-NIR detectable plastics, residual plastics and laminated flexible packages. The residual plastics (PMMA, PC, PLA, PUR, etc.) is usually a very small category and usually not further sorted. Only in the case of dedicated studies for bio-plastics this category is further divided in PLA, starch-based plastics, etc. The non-NIR detectable plastics are further divided into four categories, the laminated flexible films are divided in four categories, see Table 7 and Annex $G$ for the decision tree.

\section{Table 7: Categorisation of the residual plastic articles.}

\begin{tabular}{lll}
$\begin{array}{l}\text { Type } \\
\text { DPP }\end{array}$ & Miscellaneous polymers & $\begin{array}{l}\text { PCamples in the Netherlands } \\
\text { headlights, thermosetting plastic, rubber }\end{array}$ \\
\hline DPP & Black/low-NIR rigid packages & Shampoo-bottles, meat and fish trays, coloured hair gel tubes, \\
\hline DPP & Black/low-NIR foil <A4 & Uncommon in the Netherlands \\
DPP & Black/low-NIR foil > A4 & Compost and garden-earth bags, garbage bags \\
\hline NPP & Black/low-NIR articles & Flowerpot, bin, sunglass, coat hanger, chair, geotextile, CD packaging, black \\
\hline UPP & Metallised plastic films & cutlery, machine and appliance parts (fan, mesh, casing...), mulch film \\
\hline UPP & Pre-baked bread packages & Crisp bags, coffee pouches, nut pouches \\
\hline UPP & Meat, cheese, fish films & All flexible packaging films used as top-film, skin-film, vacuum pouch to pack \\
\hline UPP & Other laminated flexibles & meats, fish, cheese and cured meats often with EVOH, PVdC, PA.
\end{tabular}




\subsection{Sorting non-ferrous metal articles}

In recent years we obtained requests to analyse the composition of the non-ferrous metal packages and articles present in collected LWP. These LWP samples are first sorted on the material level, as explained in paragraph 4.1. A magnet is used to discriminate the ferrous from the non-ferrous metals. The non-ferrous-metals in LWP are often predominantly aluminium objects and can be divided in 12 categories, see Table 8. These categories are divided in two main types: non-ferrous metal packages (NFP) and non-ferrous metal articles (NFA). The sorting can be done by simple visual recognition.

Table 8: Categorisation of the non-ferrous metal packages and articles.

\begin{tabular}{lll} 
Type & Category & Examples in the Netherlands \\
NFP & Beverage cans & Soda beverages and beer \\
\hline NFP & Spray cans \& aerosols & Shaving foam, deodorants, paint \\
\hline NFP & Various cans and pots & Processed vegetable cans, personal care products \\
\hline NFP & Aluminium trays & Meal trays \\
\hline NFP & Tubes & Toothpaste, glue, mustard \\
\hline NFA & Aluminium foil & \\
\hline NFP & Aluminium lids and butter foil & Top-lids of beakers \\
\hline NFP & Aluminium laminate & Pouches for children beverages, cat feed etc. \\
NFP & Caps \& closures & Wine bottle capsule, screw tops for jars \\
\hline NFA & Tea lights & \\
\hline NFA & Coffee capsules & Nespresso capsules etc. \\
\hline NFA & Non-packaging articles & Electronics, walking sticks, etc. \\
\hline
\end{tabular}

\subsection{Finalising after sorting}

After the sorting of the LWP material has been carried out all the categories are weighted separately. The weights are registered in a laboratory journal as hard copy and subsequently entered in data sheets. These data sheets are communicated with clients. The hard copies of the weighing results are archived.

In a few cases all the categories are bagged, labelled and stored separately. In most cases the objects are recombined and further processed or discarded. In case a category is putrescent and is no longer used, than it is weighed and directly discarded in the outside skip. 


\section{Literature}

Brouwer, M.T., Thoden van Velzen, E.U., 2017. Recycleerbaarheid van verpakkingen op de Nederlandse markt, Wageningen Food \&Biobased Research report 1782, 1 december 2017 Wageningen, DOI 10.18174/427519.

Brouwer, M.T., Thoden van Velzen, E.U., Augustinus, A., Soethoudt, H., DeMeester, S., Ragaert, K., 2018. Predictive model for the Dutch post-consumer plastic packaging recycling system and implications for the circular economy. Waste management 71, 62-85. doi:

10.1016/j.wasman.2017.10.034 .

Duales System Deutschland (2016) Specifications. Duales System Deutschland (2016): https://www.gruener-punkt.de/en/download.html (accessed November 23, 2016).

Feil, A., Thoden van Velzen, E.U., Jansen, M., Go, N., Pretz, T., 2016. Technical assessment of processing plants as exemplified by the sorting of beverage cartons from lightweight packaging wastes. Waste Management 48, 95-105. doi: 10.1016/j.wasman.2015.10.023

Gallardo, A., Carlos, M., Colomer, F.J., Edo-Alcón, N., 2018. Analysis of the waste selective collection at drop-off systems: Case study including the income level and the seasonal variation. Waste Management \& Research 36(1), 30-38. doi: 10.1177/0734242X17733.

Leenaars, Y., Boer de, E., Thoden van Velzen, E.U., 2016. Aandeel kunststof niet-verpakkingen in gesorteerde producten. Eureco en WUR rapport, 21 april 2016, Terschuur, https://www.nedvang.nl/uploads/Eureco_-_Aandeel_kunststof_niet-verpakkingen.pdf.

Leenaars, Y., Boer de, E, 2017. Samenstelling ingezameld kunststof/PMD verpakkingen -het effect van inzamelsystemen. Eureco en WUR rapport, 26 juni 2017, Learning Centre Kunststofverpakkingsafval, Utrecht, https://www.nedvang.nl/uploads/LCKVARapportage_Samenstelling_kunststof_PMD_verpakkingen.pdf.

Nedvang, 2016. Uitvoering en monitoringsprotocol. Versie 3.0, https://www.nedvang.nl/uploads/20161223_UMP.pdf .

Thoden van Velzen, E.U., 2013. Sorteerprotocol kunststofverpakkingsafval. Wageningen Food \& Biobased research, Annex to a report, http://edepot.wur.nl/260435.

Thoden van Velzen, E.U., Brouwer, M.T., Keijsers, E., Pretz, T., Feil, A., Jansen, M., 2013. Pilot beverage cartons, extended technical report. FBR report 1440, Wageningen UR Food \& Biobased Research, http://edepot.wur.nl/293560.

Thoden van Velzen, E.U., Brouwer, M.T., Molenveld, K, 2016. Technical quality of rPET. FBR report 1661, Wageningen UR Food \& Biobased Research, http://edepot.wur.nl/392306.

Vereniging Afvalbedrijven, 2017. Factsheet acceptatieprocedure PMD op overslag- of sorteerinstallatie. https://www.verenigingafvalbedrijven.nl/fileadmin/user_upload/Documenten/PDF2017/VA_Factsh eet_Acceptatieprocedure_PMD.pdf 


\section{Annex 1 Guidelines for using the NIR scanner to sort on main polymer type}

1. Prior to sorting, the surface of the reflective tile of the NIR scanner IOSYS SIRO should first be cleaned with water and ethanol. After the liquids have evaporated, the scanner can be turned on. The scanner should always be calibrated (press F4 button on the device) after a minute, when the halogen light reaches its maximum light strength. Directly after calibration the performance of the scanner is checked by using 6 test strips of plastics (PET, PP, PE, PVC, PS, PLA). The signals should be clear and stable. PP is most sensitive for mis-readings, since the NIR spectrum closely resembles that of PVC. In case the signal is labile or faulty, the light might have to be repositioned, the tile might have to be cleaned again and the calibration will have to re-executed.

2. It is advised to re-calibrate the scanner every one or two hours, during the sorting. Additionally, it is wise to clean the reflective tile every few hours prior to recalibrations.

3. The best NIR sorting program for rigid packages is the "DSD programme" (press key " $z$ "). However, for flexible materials the "FOLIE programme" (press key "m") is more suitable. Note that the FOLIE programme is "more accurate" and also recognises the residual plastics (PLA, PC, PU, PMMA..), while the DSD programme is less accurate and does not recognise the residual plastics, but is more useful for thicker packages.

4. Always scan the largest component of the article. Most packages consist of multiple materials and then scan the heaviest component of the package. So in case of a bottle, the body is scanned and not the cap or the label.

5. Some foils, especially the thinner ones, are sometimes more difficult to identify for the NIR scanner. In that case, the foil should be folded two/three times, to enlarge the optical path for the NIR scanner and measured again. Most often the scanner than is able to identify the material.

6. The NIR scanner can produce signals, such as PE-PA, PE-PP, PE-PET, PP-PA, PP-PET..., which are common for laminated packaging films. If a visual inspection confirms that this piece of plastic could indeed be a multi-layered flexible film, then it should be added to the sorting bin laminates.

7. All aluminised packaging films and flexible packaging for meat, fish or cheese can directly be put directly to the bin for laminates.

8. In case a plastic bottle or a container is at least half-full with water or another non-sticky liquid, then pour the liquid out, and place the bottle into the bin that corresponds to the right polymer type. If the contents is sticky and dense then place the package (including the content) in the bin "organic and undefinable residues"

At the end, sample should be sorted into the six corresponding main polymer categories: PE, PP, PET, PS, PVC, Rest/low-NIR (and laminates). If there are any non-plastic materials present (metal, paper, organics etc.), they should be kept separated, weighted and these weights should be added to the previously determined weights for these material categories. 


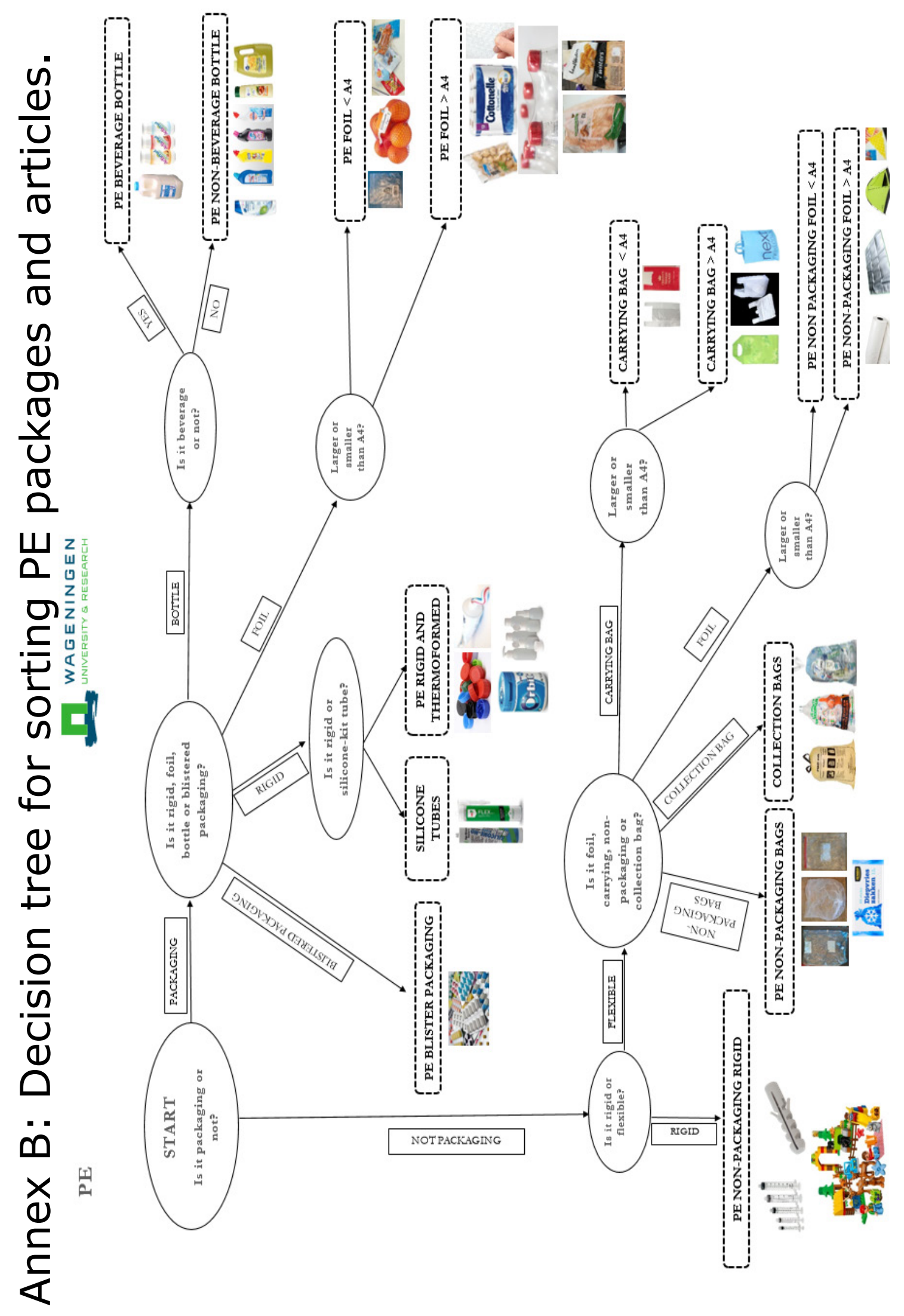




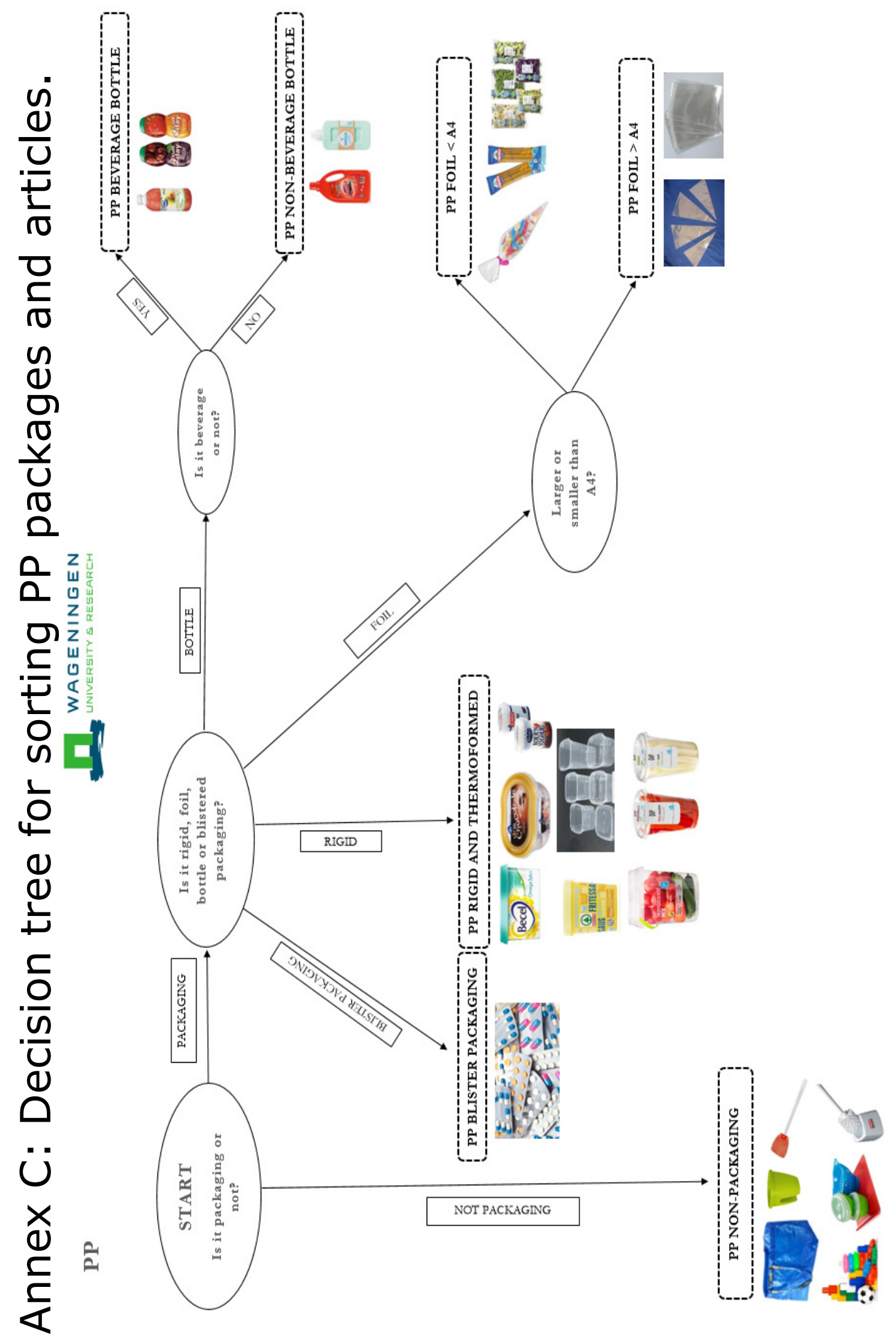




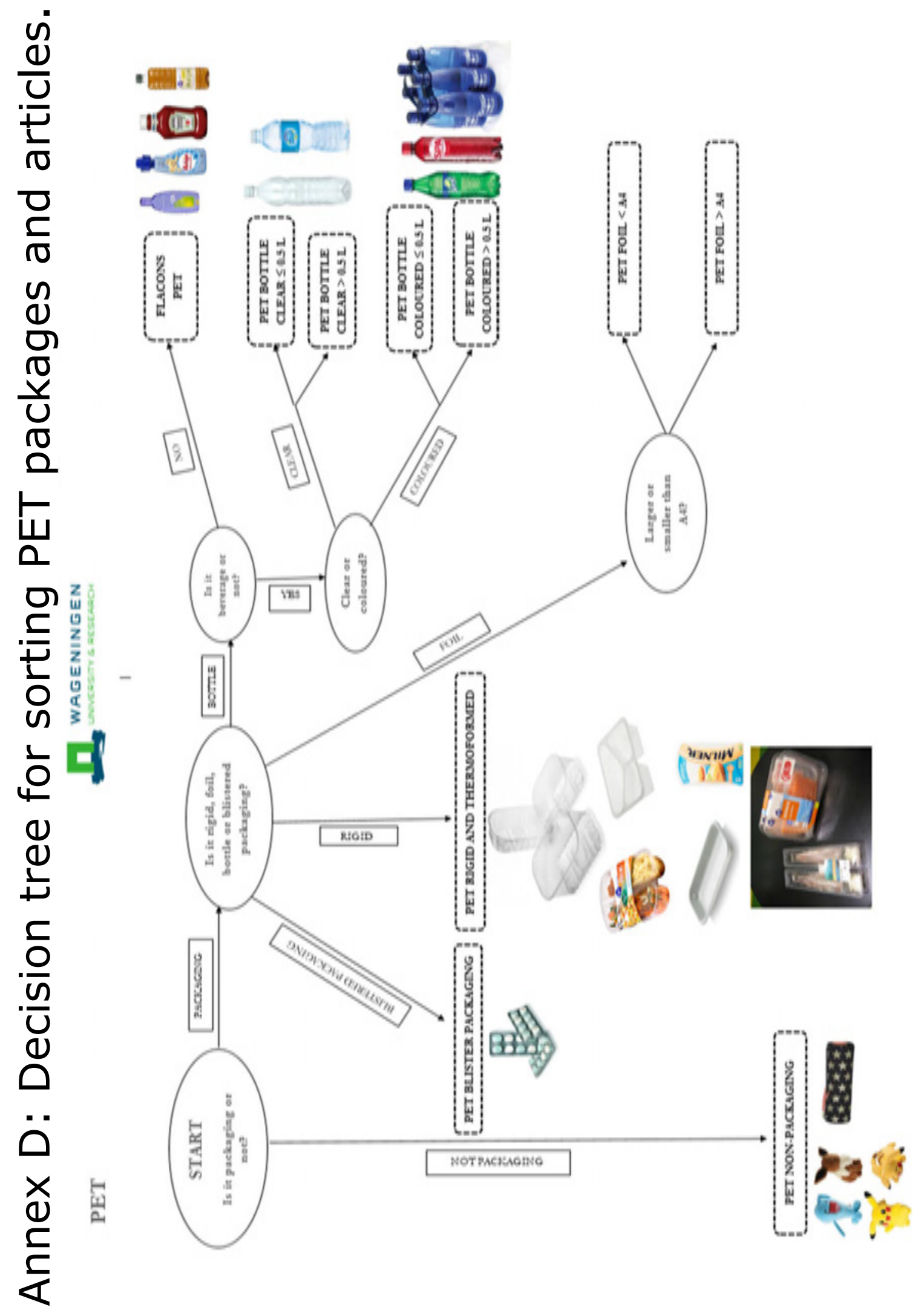




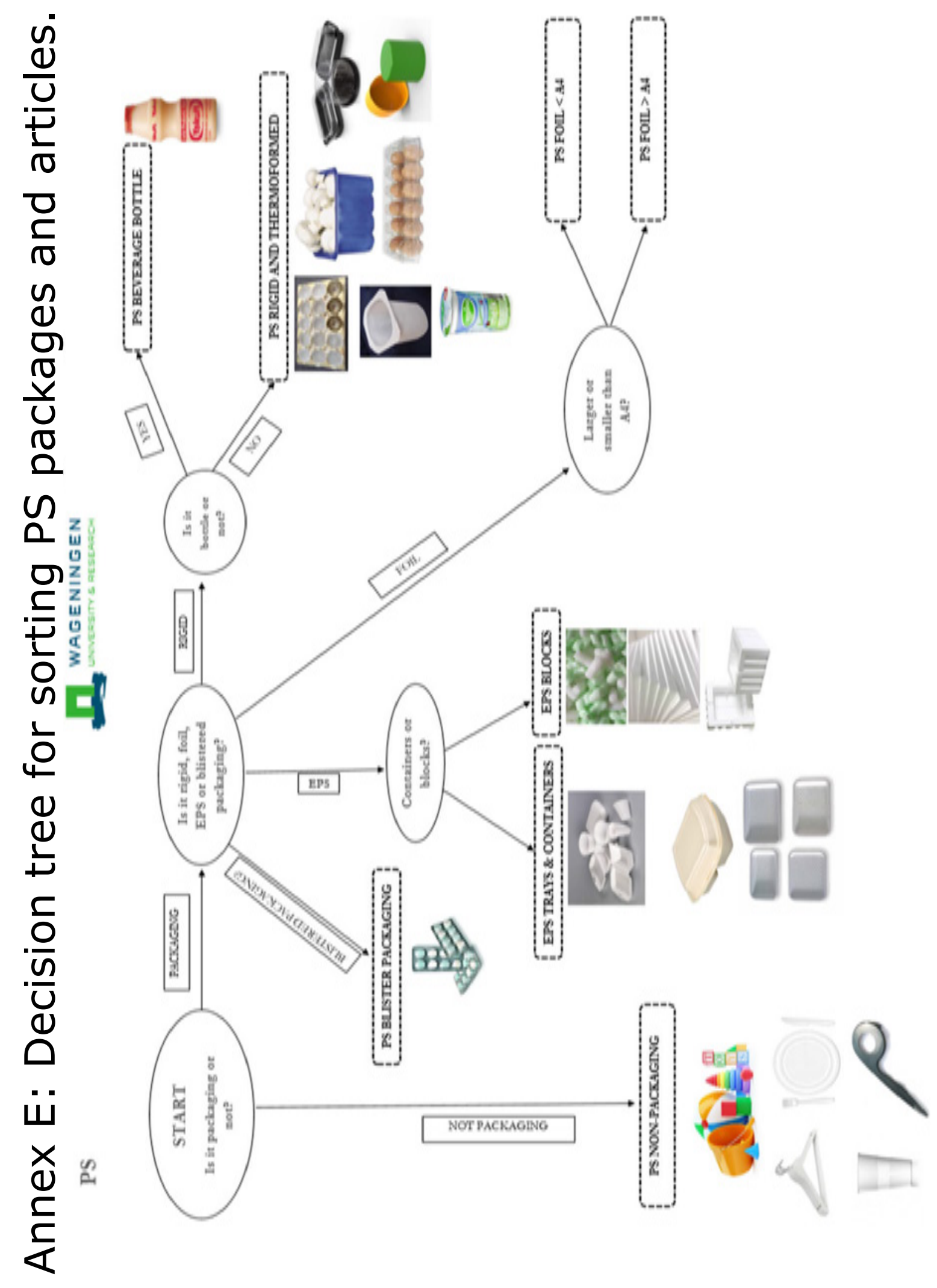




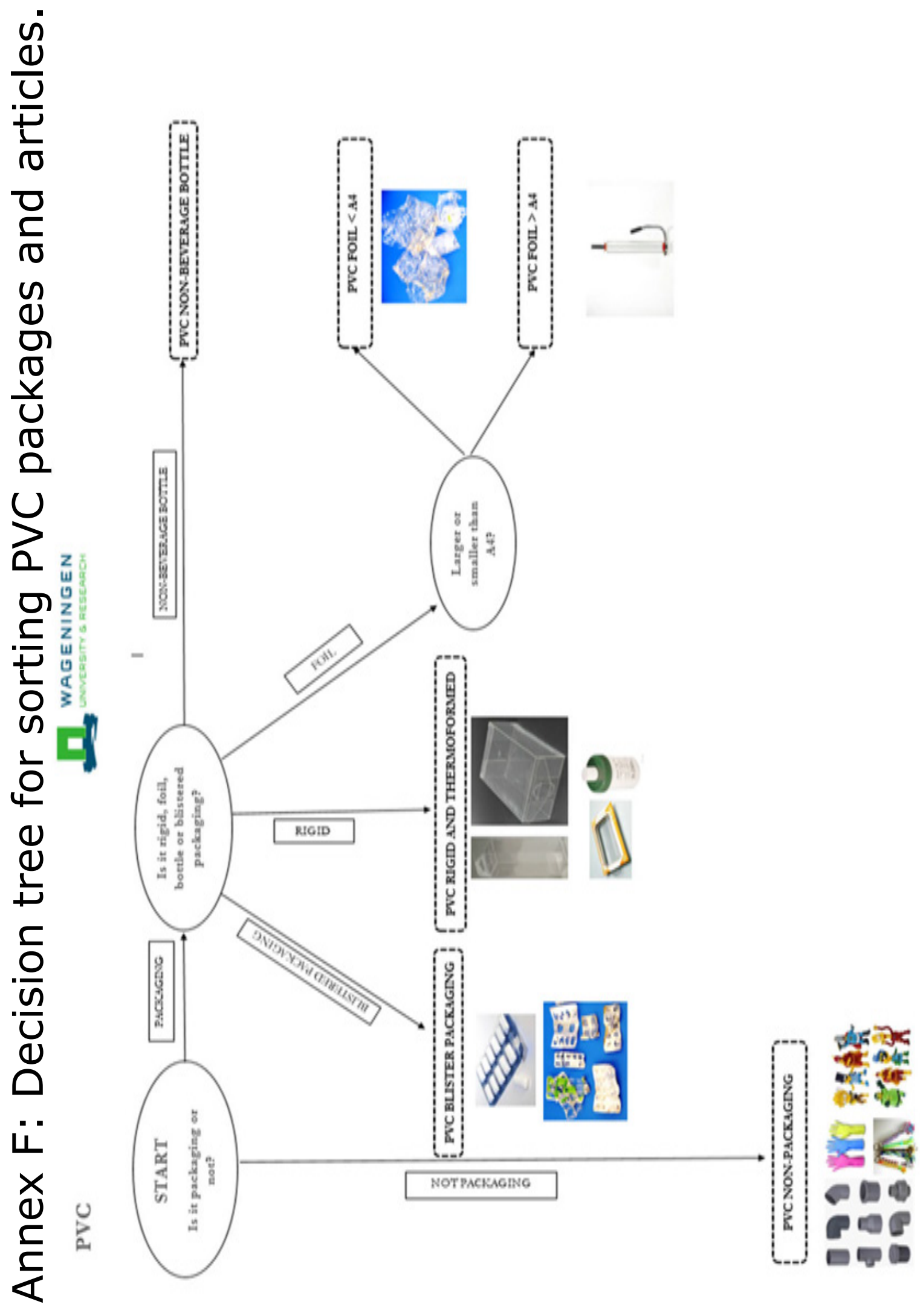




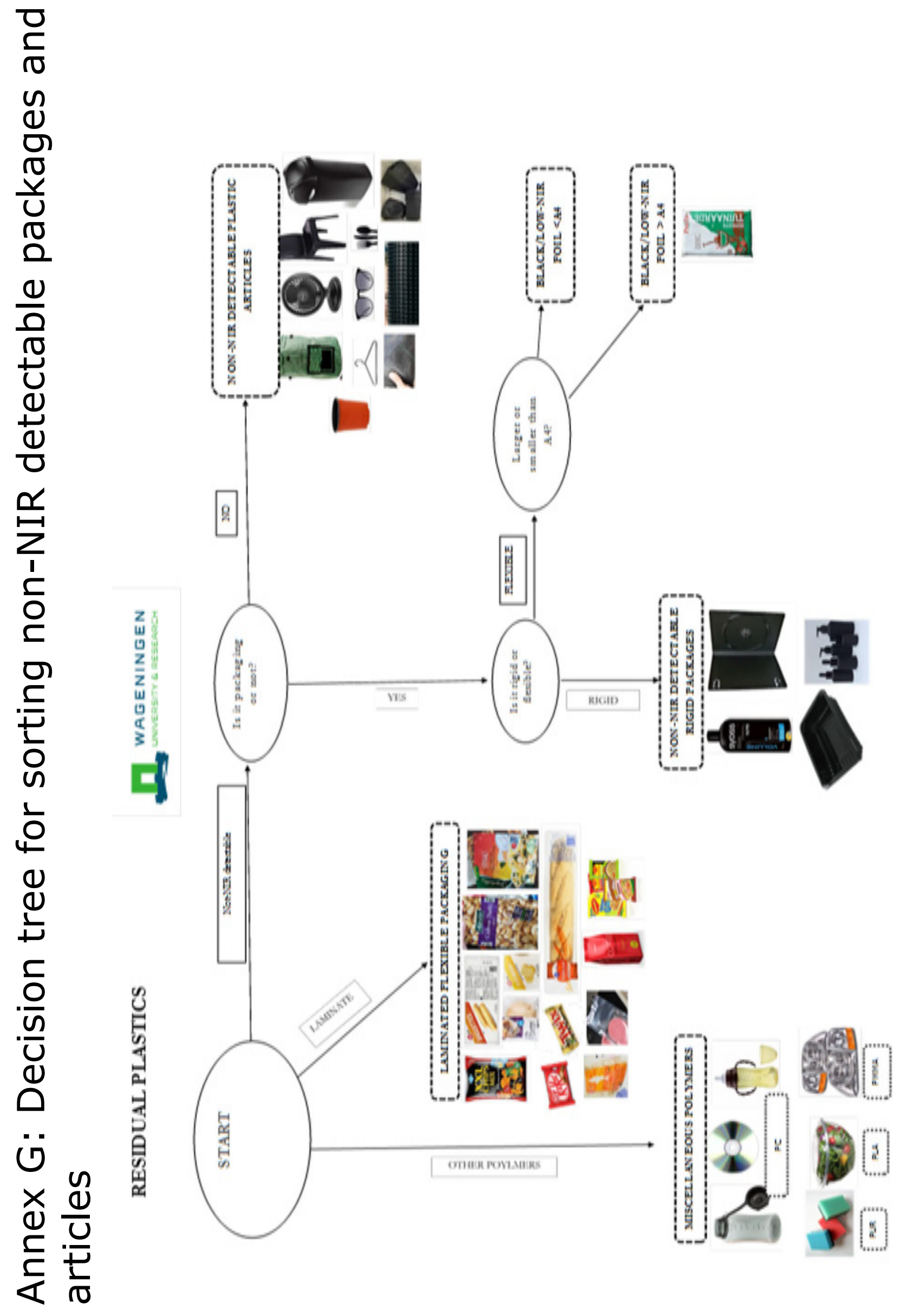





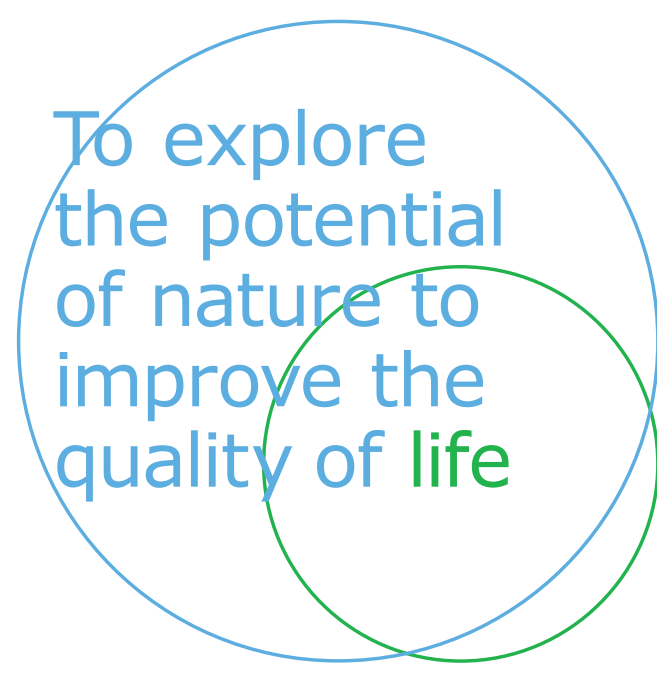

Wageningen Food \& Biobased Research Bornse Weilanden 9

6708 WG Wageningen

The Netherlands

www.wur.eu/wfbr

Einfo.wfbr@wur.nl

Report 1826

ISBN 0000-0000

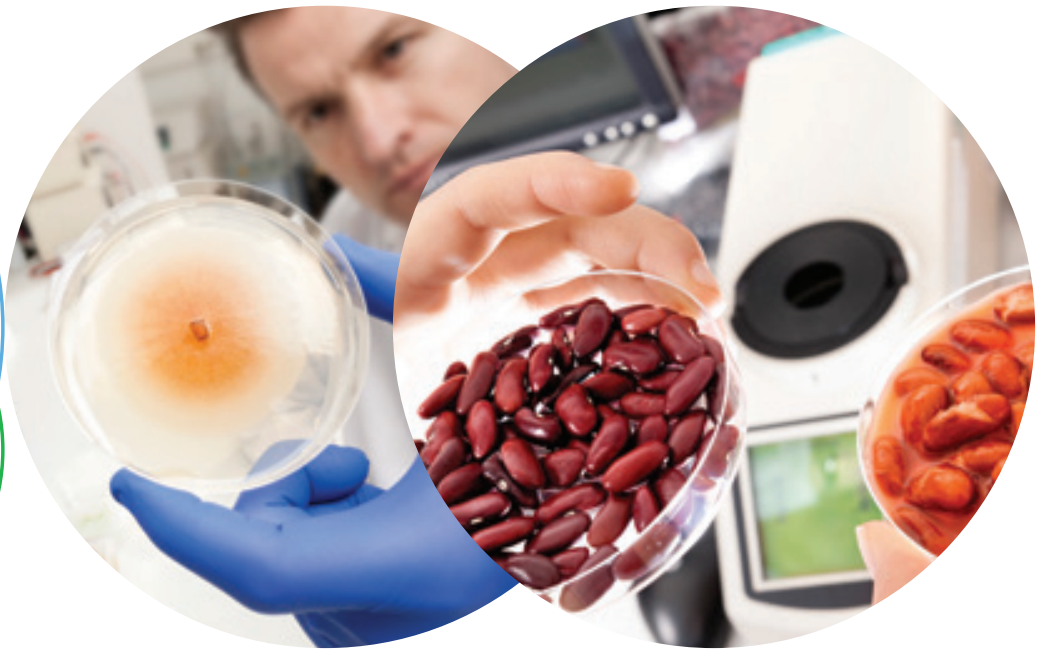

The mission of Wageningen University and Research is "To explore the potential of nature to improve the quality of life". Under the banner Wageningen University \& Research, Wageningen University and the specialised research institutes of the Wageningen Research Foundation have joined forces in contributing to finding solutions to important questions in the domain of healthy food and living environment. With its roughly 30 branches, 5,000 employees and 10,000 students, Wageningen University \& Research is one of the leading organisations in its domain. The unique Wageningen approach lies in its integrated approach to issues and the collaboration between different disciplines. 